\title{
Nutrição e vigor de mudas de cafeeiro e infestação por bicho mineiro ${ }^{1}$
}

\author{
Leaf-miner attack in relation to nutrition and vigor of coffee-tree seedlings
}

\author{
Sérgio Luiz Caixeta ${ }^{2}$ Herminia Emilia Prieto Martinez ${ }^{3}$ Marcelo Coutinho Picanço ${ }^{4}$ \\ Paulo Roberto Cecon ${ }^{5}$ Marlon Dutra Degli Esposti ${ }^{6}$ José Francisco Teixeira do Amaral $^{7}$
}

\section{RESUMO}

Avaliou-se o efeito da disponibilidade de $\mathrm{N}$ e K sobre o vigor das plantas e ataque de bicho mineiro a mudas de cafeeiro, cultivar Catuaí Vermelho IAC 99. O experimento foi conduzido em solução nutritiva e em casa de vegetação. Os tratamentos consistiram de um fatorial formado por 4 doses de $\mathrm{N}$ e 4 doses de $K$, dispostos em delineamento inteiramente ao acaso, com três repetições e duas plantas por parcela. Os adultos de bichomineiro (Leucoptera coffeella-Guérin-Ménèville) foram liberados 6 meses após o início do experimento. Dois meses após, avaliaram-se o crescimento e vigor das plantas, o ataque da praga $e$ as concentrações de $N, K$, proteína, lignina, amido e açucares solúveis totais na matéria seca das plantas. Os dados obtidos foram submetidos à análise da variância, de regressão e de correlação. De modo geral, o teor de proteína apresentou correlação positiva, enquanto os teores de lignina, amido $e$ açucares solúveis totais apresentaram correlações negativas com $o$ ataque do bicho-mineiro. As mudas de cafeeiro com nutrição nitrogenada adequada e mais vigorosas foram mais atacadas pelo inseto.

Palavras-chave: Coffea arabica, nitrogênio, potássio, interação inseto-planta.

\section{ABSTRACT}

The effects of $N$ and $K$ availabilities on both growth of coffee plant seedlings and attack by the leaf-miner (Leucoptera coffeella-Guérin-Ménèville) to these coffee plants were evaluated. The experiment was carried out in nutritive solution under greenhouse conditions. Treatments consisted of a complete factorial scheme composed by 4 doses of nitrogen and 4 of potassium on a entirely randomized design with three replicates and two plants per plot.The plants were infested with the leaf miner when they were 6 months old. Two months latv. 1,v. 1,er they were evaluated.The obtained data were submited to variance, regression and correlation analysis. Protein content presented positive correlation with the attack of the coffee leaf-miner, while the contents of lignin, starch and total soluble sugars showed a negative correlation. The stronger attack of the leaf-miner occurred in the most vigorous coffee seedlings which were provided with an adequate nitrogen nutrition.

Key words: Coffea arabica, nitrogen, potassium, interaction insect-plant.

\section{INTRODUÇÃO}

No Brasil, o bicho-mineiro (Leucoptera coffeela Guérin-Ménèville) é considerado a principal praga do cafeeiro. Este inseto é monófago, holometábolo, e sua fase larval é a única etapa do ciclo prejudicial ao cafeeiro. As lagartas consomem o parênquima paliçádico, causando necrose no limbo foliar, redução na atividade fotossintética e queda de folhas. Estes danos reduzem a longevidade do cafeeiro e a produção (SOUZA et al., 1998).

A intensidade do ataque de $L$. coffeella ao cafeeiro é influenciada pelo clima, presença de predadores e parasitóides, densidade de plantio e tratos culturais, entre outros fatores (SOUZA, et al., 1998). O estado fisiológico e características de crescimento do cafeeiro, em função de sua nutrição, também podem estar relacionados com o ataque de

${ }^{1}$ Parte da Dissertação de mestrado do primeiro autor, apresentada ao Programa de Pós-graduação em Fitotecnia da Universidade Federal de Viçosa (UFV)

${ }^{2}$ Instituto Brasileiro de Geografia e Estatística (IBGE), 78900-030, Porto Velho, RO.

${ }^{3}$ Professor Adjunto, Departamento de Fitotecnia, UFV, Av. P. H. Rolfs s/n, 36571-000, Viçosa, MG. E-mail: herminia@ufv.br

${ }^{4}$ Professor Adjunto, Departamento de Biologia Animal, UFV. E-mail: picanço@ufv.br

${ }^{5}$ Professor Adjunto, Departamento de Informática, UFV. E-mail: cecon@dpi.ufv.br

${ }^{6}$ Doutorando em Fitotecnia, Departamento de Fitotecnia, UFV.

${ }^{7}$ Professor substituto, Centro de Ciências Agrárias da Universidade Federal do Espírito Santo, 29500-000, Alegre, ES. E-mail:

jfamaral@escelsanet.com.br 
bicho-mineiro (NESTEL et al., 1994). A disponibilidade de nutrientes minerais pode influenciar a seleção do hospedeiro pelo inseto por alterar a composição química, a morfologia e anatomia, bem como a fenologia da planta (MARSCHNER, 1995).

O cafeeiro é exigente em nutrientes, principalmente nitrogênio $(\mathrm{N})$ e potássio $(\mathrm{K})$, e a época de adubação da cultura coincide com a fase crítica de ataque do bicho-mineiro. Deste modo, conforme verificado em outras culturas e com outras pragas, as quantidades de $\mathrm{N}$ e $\mathrm{K}$ fornecidas ao cafeeiro podem conferir maior tolerância ou susceptibilidade ao inseto.

O nitrogênio é importante para a síntese de aminoácidos e proteínas, que são os nutrientes limitantes para a sobrevivência dos insetos. Alta disponibilidade de $\mathrm{N}$ aumenta o teor foliar de aminoácidos e proteínas, bem como o crescimento vegetativo, retardando a maturação e lignificação dos tecidos, enquanto que, a adequada nutrição potássica aumenta essa lignificação. Por estes motivos, em geral, o N aumenta e o K reduz a incidência de pragas nas culturas (MARSCHNER, 1995). Entretanto há trabalhos mostrando que o ataque de pragas aumenta com fertilização potássica e diminui com a nitrogenada (WARING \& COBB, 1992). PHELAN et al. (1996) relatam que, na interação inseto-planta, as relações entre os nutrientes são mais importantes que os seus teores.

Até o momento, tem sido dada maior atenção aos efeitos da disponibilidade de nutrientes, principalmente $\mathrm{N}$, sobre o teor de metabólitos secundários e a relação entre estes compostos e o ataque de pragas. Os insetos especialistas de pequena dimensão e crescimento rápido são pouco afetados pela presença de compostos secundários e, possivelmente, evoluíram em ambientes com dieta rica em nutrientes (MATTSON \& SCRIBER, 1987). Além disso, as mariposas de bicho-mineiro, provavelmente selecionam plantas nutricionalmente mais adequadas para ovopositar (MICHEREFF, 2000). NESTEL et al. (1994) supõem que a densidade populacional do bicho-mineiro durante o ano esteja relacionada com o estado fisiológico da planta e com a digestibilidade das folhas para as lagartas. Assim sendo, o objetivo deste estudo foi avaliar a influência da disponibilidade de $\mathrm{N}$ e K no crescimento, concentrações foliares de N, K, proteína, lignina, amido e açúcares solúveis totais em folhas de cafeeiro, e destes no ataque do bicho-mineiro.

\section{MATERIAL E MÉTODOS}

O experimento foi conduzido em vasos contendo 9L de solução nutritiva, empregando-se mudas de café Catuaí Vermelho IAC 99. Os tratamentos consistiram de um fatorial completo, formado pela combinação das doses de $\mathrm{N}(3,7,11 \mathrm{e}$ $15 \mathrm{mmol} \mathrm{L}^{-1}$ ), sendo $20 \%$ do $\mathrm{N}$ na forma de $\mathrm{NH}_{4}^{+}$, com as doses de $\mathrm{K}\left(3,5,7\right.$ e $\left.9 \mathrm{mmol} \mathrm{L}^{-1}\right)$, dispostos em delineamento inteiramente casualizado, com três repetições e duas plantas por parcela. As concentrações utilizadas dos demais macronutrientes em mmol L ${ }^{-1}$ e dos micronutrientes em $\mu$ mol L-1 foram: $\mathrm{Ca}=4 ; \mathrm{Mg}=2 ; \mathrm{P}=0,5 ; \mathrm{S}=2 ; \mathrm{Zn}=1,5 ; \mathrm{B}=$ $46 ; \mathrm{Cu}=0,3 ; \mathrm{Mo}=0,5 ; \mathrm{Fe}=60 ; \mathrm{e} \mathrm{Mn}=36$. $\mathrm{O} \mathrm{pH}$ da solução nutritiva foi mantido entre 5,5 e 6,0.

Durante a condução do experimento, o volume e $\mathrm{pH}$ da solução nutritiva foram corrigidos diariamente em todos os vasos. A solução nutritiva foi substituída quando a concentração de $\mathrm{K}$ atingiu $50 \%$ da concentração inicial, no tratamento de menor dose de $\mathrm{K}$.

Os adultos de bicho-mineiro, necessários para infestação das mudas, foram obtidos de criatório mantido no Setor de Entomologia da UFV. A criação dos insetos foi realizada inicialmente, coletando-se folhas com pupas para posterior emergência dos adultos. Estes foram colocados em gaiolas de madeira com um metro cúbico, teladas com organza, onde mudas de cafeeiro foram utilizadas para o aumento e manutenção da população do inseto.

As mudas de cafeeiro foram infestadas com adultos do bicho mineiro aos seis meses de idade. Os adultos foram liberados e tinham livre acesso podendo selecionar qualquer planta. Quando das liberações, não foi realizada a sexagem, e nem padronizada a idade dos adultos. Foram liberados 100 mariposas/semana, nas três primeiras semanas e 200 adultos nas três semanas seguintes, totalizando 900 mariposas para um total de 96 mudas de cafeeiro.

Dois meses após o início das liberações dos adultos, avaliaram-se: produção de matéria seca/planta (MS), número de folhas/planta (NTF), área foliar/ planta (AF), tamanho médio de folhas (TAF), número de minas por planta (NM), folhas minadas/planta (NFM), porcentagem de folhas minadas (PFM=((NFM/total de folhas $) \times 100))$, concentrações foliares de N, K, proteína, lignina (TL), amido (TA) e açucares solúveis totais (TAS).

$\mathrm{O} \mathrm{N}-\mathrm{NH}_{4}{ }^{+}$foi extraído pela digestão sulfúrica,o K pela digestão nitroperclórica e o $\mathrm{N}-\mathrm{NO}_{3}{ }^{-}$ em banho-maria a $45^{\circ} \mathrm{C}$, por uma hora. Os teores nitogênio na forma amoniacal e nítrica foram determinados por colorimetria, e o $\mathrm{K}$ por fotometria de chama. O teor de $\mathrm{N}_{\text {total }}$ foi obtido pela soma das duas formas de $\mathrm{N}$ determinadas. $\mathrm{O}$ teor de proteínas foi obtido, multiplicando-se o N-NH${ }_{4}^{+}$ pelo fator 6,25 . Os açúcares totais e amido na 
matéria seca de folhas foram extraídos com água e ácido perclórico a $52 \%$ e determinados, por colorimetria, pela reação glicose-antrona-ácido sulfúrico. A lignina foi extraída em detergente ácido, e suas concentrações obtidas pelo método do permanganato de potássio.

Os dados obtidos foram submetidos às análises de variância e regressão. Os modelos foram escolhidos com base no coeficiente de determinação e na significância dos coeficientes de regressão, utilizando-se o teste " $\mathrm{t}$ ". Adotaram-se os níveis de significância de $5 \%$ e $1 \%$ de probabilidade. Estabeleceram-se as correlações lineares simples entre as características de ataque do bicho-mineiro e os teores de N, K, proteína, lignina, amido e açucares solúveis totais e as características de vigor das mudas de cafeeiro.

\section{RESULTADOS E DISCUSSÃO}

Obteve-se maior NTF (63), AF $\left(4.557,46 \mathrm{~cm}^{2}\right)$ e TAF $\left(75,26 \mathrm{~cm}^{2}\right)$ para as doses 10,48 , 10,29 e $10,12 \mathrm{mmol} \mathrm{L}^{-1}$ de N, respectivamente (Figura 1). O NTF foi a única característica de vigor influenciada pelas doses de $\mathrm{K}$, aumentando linearmente segundo a equação $\hat{Y}=58,2906+1,3448 \mathrm{~K}$ $\left(\mathrm{P}<0,05 ; \mathrm{r}^{2}=0,61\right)$. Os teores foliares de $\mathrm{K}$ em função das doses empregadas ficaram entre 3,60$3,95 \mathrm{dag} \mathrm{kg}^{-1}(\mathrm{P}<0,01)$. RODRIGUES (1997) observou teores de 2,80 $\mathrm{dagkg}^{-1}$ em mudas de cafeeiro adequadamente nutridas. Deste modo, a ausência de resposta à nutrição potássica para a maioria das características avaliadas, deveu-se ao fato de as menores doses de $\mathrm{K}$ terem atendido à demanda das mudas de cafeeiro.

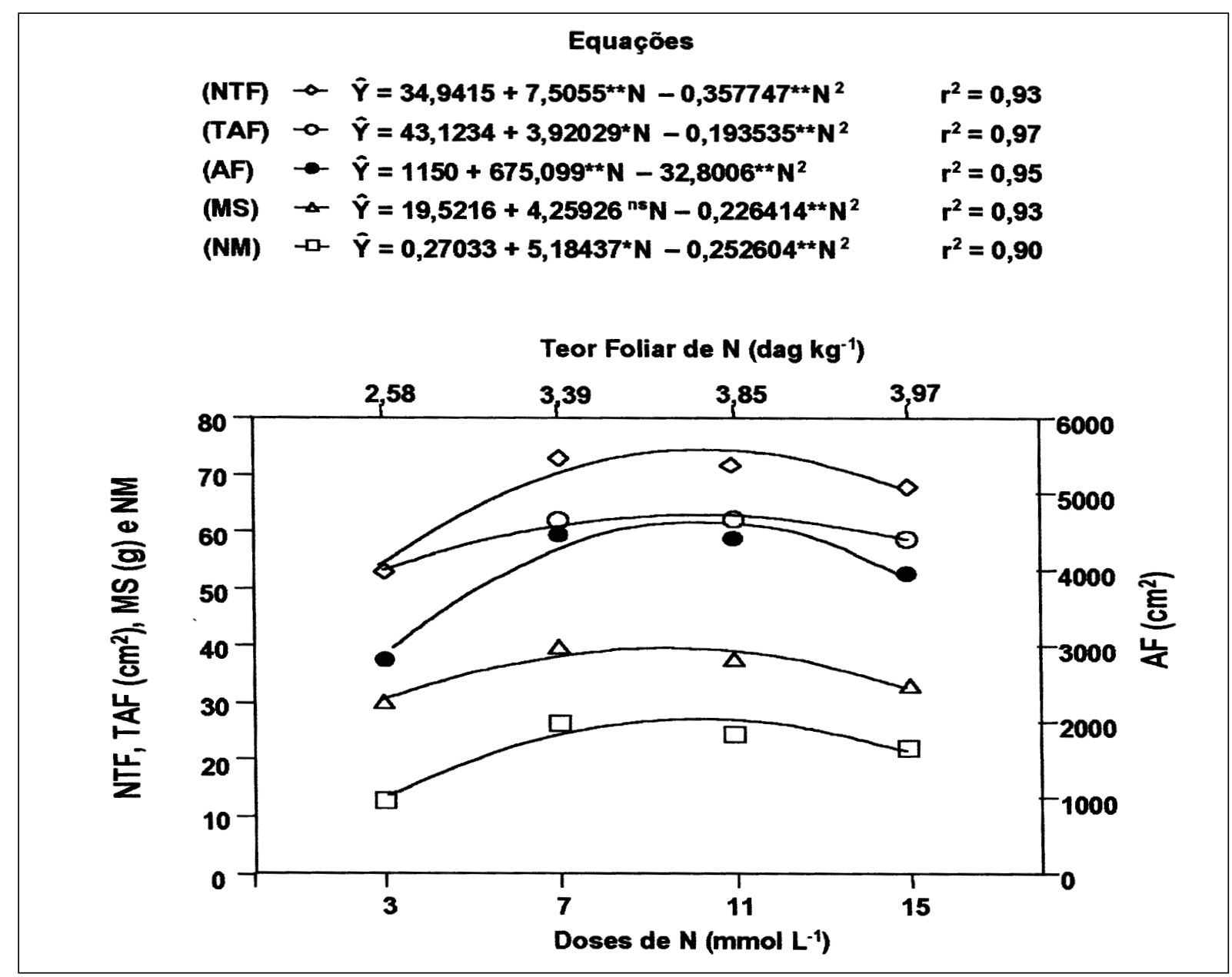

Figura 1 - Número total de folhas por planta (NTF), tamanho médio de folhas (TAF), área foliar (AF), produção de matéria seca (MS) e número de minas por planta (NM) de cafeeiro, como variáveis das doses de nitrogênio na solução nutritiva (para cada dose de $\mathrm{N}$ são mostrados os respectivos teores foliares estimados de $\mathrm{N}$ )

$* * * * \mathrm{e}^{\circ}=$ Significativo ao nível de 1,5 e $10 \%$, respectivamente, pelo teste $\mathrm{F}$.

Ciência Rural, v. 34, n.5, set-out, 2004. 
A preferência de ataque do bicho-mineiro foi mensurada pelo NM por planta, o qual variou segundo uma função quadrática com as doses de $\mathrm{N}$ aplicadas. $\mathrm{O}$ maior número de minas por planta (27minas) foi obtido na dose $10,26 \mathrm{mmol} \mathrm{L}^{-1}$ de $\mathrm{N}$, correspondendo ao teor foliar de 3,79 dag $\mathrm{kg}^{-1}$ de $\mathrm{N}(\mathrm{P}<0,01)$. O número de minas neste ponto foi $99 \%$ maior que na dose de $3 \mathrm{mmol} \mathrm{L}^{-1} \mathrm{de}$ $\mathrm{Ne} 26,8 \%$ maior que na dose de $15 \mathrm{mmol} \mathrm{L}^{-1}$ de N (Figura 1). O resultado assemelha-se ao obtido por BRUYN et al. (2002), que observaram melhor performance de Agromyza nigripes (Diptera:Agromyzidae) em plantas de Holcus lanatus $\boldsymbol{L}$. nos tratamentos com níveis médios de adubação. Segundo WARING \& COBB (1992) a resposta positiva dos insetos à disponibilidade de nutrientes apresenta limites, ou seja, acima de um determinado teor do nutriente, a preferência dos insetos pelo hospedeiro reduz-se ou torna-se indiferente, como constatado neste trabalho.

O máximo crescimento das plantas $(39,5 \mathrm{~g}$ planta $^{-1}$ ) foi obtido com a dose de $9,4 \mathrm{mmol} \mathrm{L}^{-1}$ de $\mathrm{N}$, que correspondeu a um teor foliar de $3,71 \mathrm{dag} \mathrm{kg}^{-1} \mathrm{de}$ $\mathrm{N}$. A proximidade entre os teores de $\mathrm{N}$ associados ao maior número de minas e maior crescimento permite afirmar que as mariposas de bicho-mineiro selecionam preferencialmente plantas com adequada nutrição nitrogenada. Este resultado contraria a hipótese de que o desequilíbrio nutricional das plantas favorece o ataque de pragas (PRICE, 1991; PHELAN et al.,1996), mas está de acordo com a hipótese do vigor da planta (PRICE, 1991).

As correlações significativas e positivas entre teor foliar de $\mathrm{N}$ e NM $(\mathrm{r}=0,41, \mathrm{P}<0,01)$ e teor foliar de $\mathrm{N}$ e NFM $(\mathrm{r}=0,30, \mathrm{P}<0,05)$, indicam que $\mathrm{o}$ aumento na disponibilidade de $\mathrm{N}$ favorece o ataque do ataque do bicho-mineiro, o que também ocorreu com outras culturas (BENTZ et al., 1995; WARING \& COBB 1992).

O NM é função da seleção do hospedeiro pelas mariposas para oviposição e da alimentação e sobrevivência das lagartas. A coloração das folhas do cafeeiro é importante para a seleção das plantas pelo bicho-mineiro, sendo que este inseto prefere ovipositar em folhas verdes que sobre as amarelas (MATOS, 2001). A dose de $10,26 \mathrm{mmol} \mathrm{L}^{-1}$ de $\mathrm{N}$ pode ter resultado em folhas de coloração mais atrativa para os adultos ou proporcionado dieta adequada para as larvas, conduzindo ao maior número de minas. As plantas nutridas com as menores e maiores doses de $\mathrm{N}$, podem ter sido menos selecionadas para oviposição ou ter causado mortalidade dos primeiros ínstares das lagartas, devido à presença de compostos tóxicos ou de dieta inadequada.

As mariposas do bicho-mineiro preferem ovipositar no terceiro ou quarto pares de folhas e naquelas isentas de ovos (MICHEREFF, 2000). As mudas de cafeeiro com maior área foliar e número total de folhas, possivelmente, proporcionaram maior número de folhas isentas de postura, o que pode ser uma explicação para as correlações significativas e positivas entre NM e NTF $(r=0,32$, $\mathrm{P}<0,05)$, bem como entre $\mathrm{NM}$ e TAF $(\mathrm{r}=0,45$, $\mathrm{P}<0,01)$. No entanto, MEDINA FILHO et al. (1977) não constataram diferenças de incidência desta praga em algumas espécies de café com folhas de tamanho variáveis. Assim, o TAF, mesmo apresentando a maior correlação com o número de minas, não pode ser considerada como uma característica explicativa importante do ataque do bicho-mineiro.

O NFM (Figura 2) é um índice que expressa bem a intensidade de danos causados pela praga, pois a folha minada irá senescer primeiro que as folhas não atacadas, causando a redução da área fotossinteticamente ativa. Os maiores valores do NFM foram obtidos para as doses de $\mathrm{N}$ próximas ao adequado (figura $2 \mathrm{~b}$ ) e para as maiores doses de $\mathrm{K}$ (figura 2a). Assim, constata-se que o excesso de $\mathrm{K}$ e a nutrição nitrogenada adequada aumentam a intensidade do ataque do bicho-mineiro.

Em lavouras comerciais, a porcentagem de folhas minadas (índice relativo do número de folhas minadas) é utilizada para avaliar a necessidade de controle de bicho-mineiro, em plantas adultas. O nível de dano econômico é atingido, quando $20 \%$ das folhas amostradas no terço superior da planta estão minadas (SOUZA et al., 1998). Comparando a PFM, obtida no experimento com este índice, verifica-se que o nível de dano econômico foi atingido. Portanto, pode-se afirmar que a quantidade de mariposas liberadas foi suficiente para avaliação do ataque da praga.

Verifica-se que os menores TL foram obtidos para as doses de $\mathrm{N}$ próximas àquela que proporcionou o maior crescimento das plantas, possivelmente em virtude de uma maior produção de folhas novas e menor lignificação das mesmas. O decréscimo em TAS e TA, e o aumento nos teores de proteína com o acréscimo na disponibilidade de $\mathrm{N}$, provavelmente ocorreram devido à partição de fotoassimilados preferencialmente para a síntese de proteínas (Figuras 2 e 3). As plantas fertilizadas com altas doses de $\mathrm{N}$ aumentam a síntese de proteínas e a demanda por carboidratos (PAHLSSON, 1992). O aumento nos TL e TAS com o acréscimo nas doses de $\mathrm{K}$ é devido, possivelmente, à participação do $\mathrm{K}$ na síntese e transporte de carboidratos e na lignificação dos tecidos (MARSCHNER, 1995). 
Os teores de $\mathrm{N}_{\text {total }}$ e de proteína correlacionaram-se positivamente com as características de intensidade de ataque de bichomineiro $\left(\mathrm{N}_{\text {tota }} \times \mathrm{NM}, \mathrm{r}=0,41, \mathrm{P}<0,01\right.$; Proteína $\times \mathrm{NM}$ $\mathrm{r}=0,31 \mathrm{P}<0,01 ; \mathrm{N}_{\text {total }} \times \mathrm{NFM}, \mathrm{r}=0,30, \mathrm{P}<0,05$; Proteína $x \mathrm{NFM}, \mathrm{r}=0,27, \mathrm{P}<0,05)$ enquanto que os teores de carboidratos correlacionaram-se negativamente (TAS x NM, $\mathrm{r}=-0,48, \mathrm{P}<0,01$; TA $\mathrm{x}$ $\mathrm{NM}, \mathrm{r}=-0,30, \mathrm{P}<0,05$; TL $x \mathrm{NM}, \mathrm{r}=-0,33, \mathrm{P}<0,05$; TL $x$ NFM, $r=-0,24, P<0,05)$. A lignina é considerada um composto redutor de digestibilidade do alimento de insetos (MATTSON \& SCRIBER, 1987) e, quando presente em altas concentrações no tecido foliar, pode causar toxicidade às larvas, ou reduzir a oviposição dos adultos, conferindo à planta maior resistência contra pragas. Os carboidratos, tais como o amido e açúcares solúveis totais, não são considerados nutrientes essenciais para os insetos, pois, podem ser substituídos por proteínas como fonte de energia(PANIZZI \& PARRA, 1991).Além disso, há relatos do efeito prejudicial do acréscimo nos teores de açúcares solúveis, para alguns insetos (BERENBAUM, 1995). É provável que o aumento nos teores foliares destes compostos tenha reduzido a preferência do bicho-mineiro pelo hospedeiro, ou causado a morte de suas larvas, levando às correlações negativas observadas.

O teor foliar de proteína e sua composição em aminoácidos são os dois fatores críticos na dieta dos fitófagos (MATTSON, 1980). Supõe-se que o bicho-mineiro seja exigente quanto ao teor foliar de proteínas para o desenvolvimento larval, pois, a espécie $\boldsymbol{C}$. stenophylla $\mathrm{G}$. Don., resistente ao bicho-mineiro, contém menor teor de proteínas solúveis do que a variedade $\boldsymbol{C}$. arabica que é suscetível à praga (VALENCIA-JIMENÉZ et al.,1997). Além disso, a parte da planta em que é realizada a postura e o seu hábito minador são indicativos da influência do valor nutritivo da planta hospedeira para a seleção e sobrevivência

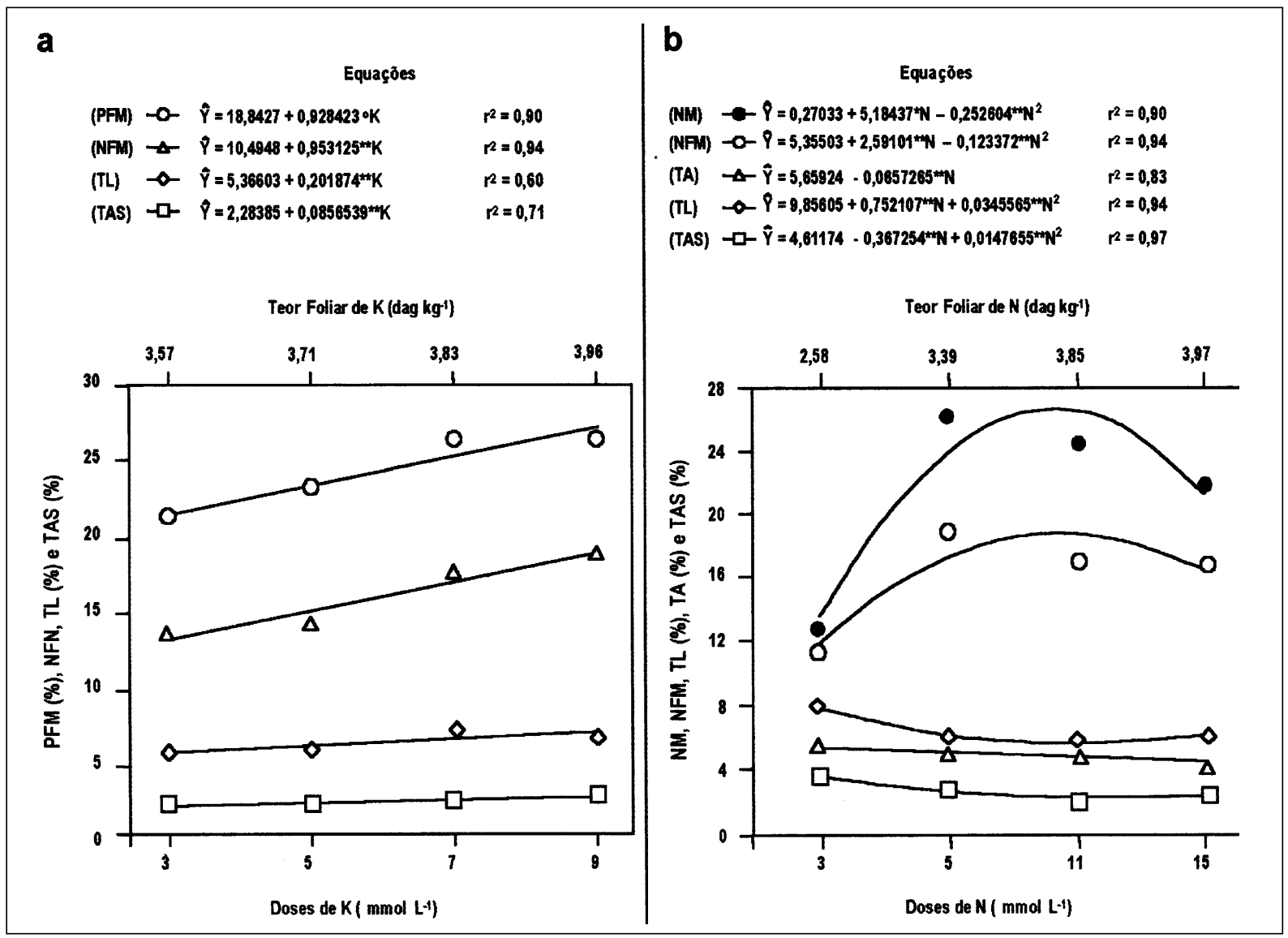

Figura 2 - (a) Porcentagem de folhas minadas (PFM), número de folhas minadas (NFM), teores foliares de lignina (TL) e de açúcares solúveis totais (TAS) em folhas de cafeeiro, como variáveis das doses de K na solução nutritiva; (b) - Número de minas (NM) e de folhas minadas (NFM), teores foliares de lignina (TL), amido (TA), e açúcares solúveis totais (TAS) em folhas de cafeeiro, como variáveis das doses de $\mathrm{N}$ na solução nutritiva (para cada dose de $\mathrm{N}$ ou $\mathrm{K}$ são mostrados os respectivos teores foliares estimados desses nutrientes).

$* * * \mathrm{e}^{\mathrm{o}}=$ Significativo ao nível de 1,5 e $10 \%$, respectivamente, pelo teste $\mathrm{F}$.

Ciência Rural, v. 34, n.5, set-out, 2004. 
$\mathrm{Y}=9,52083+1,63495 \mathrm{~N}-0,0578257 * * \mathrm{~N}^{2}+1,07099 \mathrm{~K}-0,115743 * * \mathrm{~K}^{2} ; \mathrm{R}^{2}=0,96$

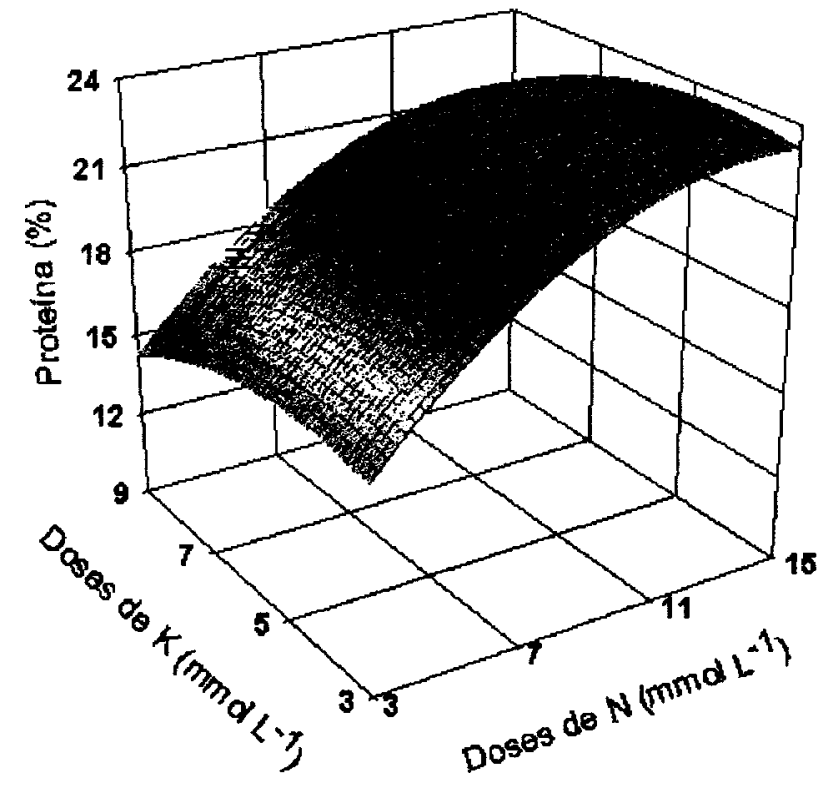

Figura 3 -Estimativa do teor de proteína na matéria seca de folhas em função de doses de N e K.

do inseto. As mariposas ovipositam, preferencialmente, no terço superior do cafeeiro e no terceiro e quarto pares de folhas a partir do ápice do ramo (NANTES \& PARRA, 1977). As larvas alimentam-se do parênquima paliçádico (SOUZA, 1998). Estas partes da planta apresentam maior atividade fotossintética e maior teor protéico (FAHAL et al., 1994). Portanto, dentre os compostos avaliados, o teor foliar de proteína, provavelmente, seja o determinante para o ataque do bicho-mineiro.

\section{CONCLUSÕES}

A adequada nutrição nitrogenada e o excesso de potássio aumentam a intensidade de ataque do bicho-mineiro ao cafeeiro. $\mathrm{O}$ aumento nos teores de proteínas e decréscimo nos teores de lignina, amido e açúcares solúveis totais estão relacionados com maior intensidade de ataque do bicho-mineiro.

A hipótese do vigor da planta é válida para a interação bicho-mineiro mudas de cafeeiro.

\section{AGRADECIMENTOS}

Os autores agradecem à FAPEMIG pelo auxílio financeiro concedido.

\section{REFERÊNCIAS BIBLIOGRÁFICAS}

BENTZ, J. et al. Nitrogen fertilizer effect on selection, acceptance, and suitability of Euphorbia pulcherrima (Euphorbiaceae) as a host plant to Bemisia tabaci (Homoptera: Aleyrodidae). Environmental Entomology, v.24, n.1, p.40-45, 1995.

BERENBAUM, M.R. Turnabout is fair play: secondary roles for primary compounds. Journal of Chemical Ecology, v.21, n.7,p.925-940, 1995.

BRUYN, L. DE; SCHEIRS, J.; VERHAGEN, R. Nutrient stress, host plant quality and herbivore performance of a leaf-mining fly on grass. Oecologia, v.130, n.4, p.594-599, 2002.

FAHAL, J.I. et al. Nitrogen and irradiance levels affecting net photosynthesis and growth of young coffee plants (Coffea arabica L.). Journal of Horticultural Science, v.69, p.161169, 1994.

MARSCHNER, H. Mineral nutrition of higher plants. 2.ed. San Diego : Academic, 1995. 889p.

MATOS, J.W. Expressão da resistência ao bicho-mineiro em Coffea canephora e Coffea congensis. 2001. 75f. Dissertação (Mestrado em Melhoramento Genético Vegetal) - Instituto Agronômico de Campinas.

ATTSON, W.J. Herbivory in relation to plant nitrogen content. Annual Review of Ecology and Systematics, v.11, p.119-161, 1980.

MATTSON, W.J.; SCRIBER, J.M. Nutritional ecology of insect folivores of woody plants: nitrogen, water, fiber, and mineral considerations. In. SLANSKY, F.; RODRIGUEZ, J.G. 
(eds.). Nutritional ecology of insects, mites, spiders and related invertebrates. New York: John Wiley, 1987. p.105146.

MEDINA FILHO, H.P.; CARVALHO, A.; MONACO, L.C. Observações sobre a resistência do cafeeiro ao bicho-mineiro. Bragantia, v.36, n.11, p.131-137, 1977.

MICHEREFF, M.F.F. Comportamento reprodutivo do bichomineiro do cafeeiro, Leucoptera coffeella (Guérin-Mèneville, 1842)(Lepidoptera : Lyonetiidae). 2000. 46f. Dissertação (Mestrado em Entomologia Agrícola) - Universidade Federal de Viçosa.

NANTES, J.F.D.; PARRA, J.R.P. Avaliação de danos causados por Perileucoptera coffella (Guérin-Méneville, 1842) (Lepidoptera-Lyonetiidae), em três variedades de café (Coffea spp.). O solo, v.69, p.26-29, 1977.

NESTEL, D.; DICKSCHEN, F.; ALTIERI, M. A. Seasonal and spatial population loads of a tropical insect: the case of the coffee leaf-miner in Mexico. Ecological Entomology, v.19, n.2, p.159167, 1994

PAHLSSON, A.B. Influence of nitrogen fertilization on minerals, carbohydrates, amino acids and phenolic compounds in beech (Fagus sylvatica L.) leaves. Tree Physiology, v.10, p.93-100, 1992

PANIZZI, A.R.; PARRA, J.R.P. (Eds.) Ecologia nutricional de insetos e suas implicações no manejo de pragas. São
Paulo: Manole, 1991. 359p.

PHELAN, P.L.; NORRIS, K.H.; MASON, J.F. SoilManagement history and host preference by $O$ strinia nubilalis: Evidence for plant mineral balance mediating insect-plant interactions. Environmental Entomology, v.25, n.6, p.13291336, 1996.

PRICE, P.W. The plant vigor hypothesis and herbivore attack. Oikos, v.62, p.244-251, 1991.

RODRIGUES, L.A. Crescimento e composição mineral na parte aérea e nas raízes de duas variedades de café em resposta à calagem na subsuperfície do solo. 1997. 89f. Dissertação (Mestrado em Fitotecnia) - Universidade Federal de Viçosa.

SOUZA, J.C. de; REIS, P.R.; RIGINATO, R.L.O. Bicho-Mineiro do cafeeiro: biologia, danos e manejo integrado. 2.ed. Belo Horizonte : EPAMIG, 1998. 48p.

VALENCIA-JIMENÉZ, A.; RIAÑO-HERRERA, N.M; SOTO-AGUDELO, J.D. Actividade de la ribulosa 1,5difosfato carboxilasa y contenidos de clorofila y proteina foliar soluble en seis genotipos de Coffea sp. Cenicafé, v.48, p.5-11, 1997.

WARING, G.L.; COBB, N.S. The impact of plant stress on herbivore population dynamics. In: BERNAYS, E. (Ed.). Insectplant interactions. London: CRC, 1992. V.4, p.167-226. 